\title{
Individual Resilience in the Organization in the Face of Crisis: Study of the Concept in the Context of COVID-19
}

\author{
Bechir Mokline $^{1}$ (I) Mohamed Anis Ben Abdallah ${ }^{2}$
}

Received: 18 March 2021 / Accepted: 18 May 2021/Published online: 22 June 2021

(C) Global Institute of Flexible Systems Management 2021

\begin{abstract}
In the context of a health crisis of unprecedented magnitude that we have experienced such as COVID-19 we join the efforts of practitioners and researchers to answer the question: 'What is the organizational context that promotes individual adaptation in a context of adversity?'. Specifically, our research aims to explore organizational practices that promote individual resilience in a COVID-19 crisis situation and in a Tunisian context. Therefore, we believe that the paradigm (resilience in the face of the COVID-19 crisis) and the context (Tunisian) both constitute the originality of our article. Our research contribution consists in demonstrating that the company has a managerial need to strengthen the psychological protective factors of its employees, which will promote their individual resilience in the organization. This necessarily leads it to develop the individual's defense mechanisms against trauma, psychological reconstruction and post-resilience learning. This modeling of resilience allowed us to observe and recognize it in sixteen Tunisian companies by using a qualitative study based on sixteen semi-structured interviews analyzed by the 'Nvivo 12' software in order to explore the functioning of individual resilience in a real organizational context.
\end{abstract}

Bechir Mokline

bechir.mokline@gmail.com

Mohamed Anis Ben Abdallah

mohamedanisbenabdallah@yahoo.fr

1 Department of Management, Faculty of Economics and Management of Nabeul, 17, rue du 1er Mai, 8020 Soliman, Tunisie

2 Faculty of Economics and Management of Nabeul, Campus Universitaire Mrezgua, 8000 Nabeul, Tunisia
Keywords Company · COVID-19 · Crisis · Individual · Organization $\cdot$ Resilience

\section{Introduction}

Nowadays, it seems that the world has to deal with a high level of risk - whether from technological, political, natural, social, or economic origins-and an increasing frequency of crises. As a result, the ability of organizations to keep efficient and sustained is diminishing as their environments become more turbulent, complex and more vulnerable to crises.

The COVID-19 crisis has confirmed these assumptions. Beyond the unprecedented nature of this health crisis, we observe that no sector of activity is exempt and that all organizations are affected. The repercussions are political, social, societal, economic and financial as well as organizational (Ahmed et al., 2021; Elias, 2021; Frimousse \& Peretti, 2020; Paramita et al., 2021; Paul \& Chowdhury, 2020; Ufua et al. 2021).

In this current crisis that is unprecedented in scale and intensity since the Second World War, organizations cannot provide preconceived responses through the establishment of conventional emergency procedures to ensure their stability (Ahmed et al., 2021; Gajdzik \& Wolniak, 2021).

The importance of the concept of resilience emerges in this context: 'By absorbing shocks, resilience is a necessary capacity for survival in a turbulent environment' (Altintas \& Royer, 2009, p.18). The concept of resilience is developed in literature on crisis management that aims to study the different dynamics and causes that can cause crises and the best responses and/or practices enabling organizations to withstand adversity and cope with 
environmental turbulence (Blyth \& Mallett, 2020; Polas \& Raju, 2021; Tam et al., 2021).

Resilience of Latin origin 'resilire': jumping backward, withdrawing and bouncing express the attitude of a system or organization to resist constraints with minimal damage.

In psychology, it refers to the individual's ability to withstand trauma, bounce back from adversity and fall back on his feet despite the setbacks of life. From this perspective, Cyrulnik (2002) defines resilience as an intrinsic quality of the individual that allows him to overcome his suffering, learn from his painful experiences and become stronger.

Most of the works that has studied the process of resilience of the individual up to that point emanates from psychology and deals with cases of early childhood or difficult adolescence (death, abuse, alcoholism of parents, rape, loss of a loved one ...) (Cyrulnik, 2003). As a result, we can ask here, like does Poirot (2007): 'Why study individual resilience from an organizational point of view?'.

We believe that it has become necessary to understand what fosters resilience in a global context of hyper-competition, complexity, crises and constant change. In such environment, everyone is limited in his or her ability to anticipate and adapt to demand and organizational events (Evans \& Bahrami, 2020; Weick et al., 1999). However, the adaptive capacity of the organization depends mainly on the adaptive capacity of its employees. Therefore, promoting resilience is fundamental to enable individuals to cope with the current context of organizations (Taylor et al., 2019).

In the context of a health crisis of unprecedented magnitude that we have experienced such as COVID-19, we join the efforts of practitioners and researchers to answer the question: 'What is the organizational context that promotes individual adaptation in a context of adversity?'. Specifically, our research aims to explore organizational practices that promote individual resilience in a crisis.

To do this, we propose first, a quick review of literature on crisis. Then, we shed theoretical light on individual resilience in psychology by jointly revealing its four phases: trauma, coping, reconstruction and post-resilience learning. Next, we present the responses of organizations to individual resilience face to adversity which are linked to three theoretical areas: structuring, emotion and leadership.

Finally, we detail the methodological aspects of data collection and processing on the one hand. On the other hand, we present our empirical results in the light of semistructured interviews with sixteen people belonging to sixteen Tunisian companies that faced difficulty as a result of the negative repercussions of the 'COVID-19' crisis but were still able to survive following the great containment.
We finish with the discussions and conclusions of the research.

\section{Individual Resilience in Psychology}

Individual resilience can be defined as the ability of individuals placed in adverse circumstances to 'get by' and still lead a satisfactory life (Michaud, 1999). Therefore, individual psychological resilience is to be able, after experiencing a terrible traumatic shock, to defend oneself, adapt to it and gradually rebuild and thus avoid depression (and sometimes to rebound) (Genet \& Siemer, 2011).

According to Szerman (2006), the resilience of the individual is not an innate quality that one possesses at birth. Rather, it is formed over time and through his family and social environment: 'Resilience is not a state that freezes us, it is a process in continuous movement of adaptation and sometimes even of creation' (Brissiaud, 2008, p.23). Therefore, we should rather rejoice in this because it leaves everyone with the hope of being able to resist and bounce back from the traumas of tomorrow (Hines et al., 2021).

In this sense, we will present the results of the work that has specifically addressed the concept under the process approach. Indeed, considering the concept of individual resilience as a process helps to understand what the company and its management must put in place so as the resilience of the individuals who compose it to work positively in the organization.

Just as Stein et al. (2000) point out, the resilience process is iterative and alternates periods: strong adaptation to stressful situations, development of protective factors and rebound and post-crisis responses without ever imagining that one day the right triggers/functioning of resilience can be mastered. 'The acquired capacity is not static but is continually affected by changes in contexts (p.17).'

However, let us break down in detail the four main aspects of the resilience process that are trauma, defense and adaptation stage of coping, reconstruction phase and post-resilience learning phase by filtering into the important literature on the subject what we think is useful to reuse in order to better approach the understanding of individual resilience in the organization.

\section{Trauma}

We cannot talk about resilience without mention of trauma: 'Resilience can only be said if there has been a traumatic tear, otherwise it is an ordeal' (Cyrulnik \& Elkaîm, 2009, p.12). Trauma can suddenly come from a violent disruptive element (rape, death of a loved one...) or gradually (a 
situation too negatively stressful professionally, the effect of dismissal, separation ...) (Chen \& Bonanno, 2020).

The unpredictable situation causes the individual to start stress that he must contain serenely in order not to reach an outdated stage of stress. It is accepted that bad stress is not a trauma for the individual until it reaches over time to the state of exceeded stress, that is when the individual who suffers from it cannot adapt to overcome it. The persistence of outdated stress could cause a total lack of understanding of the meaning of what surrounds the individual. After the shock, he no longer wants/knows what meaning to give to his life today and tomorrow (Chen \& Bonanno, 2020; Szerman, 2006). It requires that the process of resilience be triggered with a first action to regain the sense already lost before depression or another serious mental illness is triggered before it (Cyrulnik, 2004). The first action should be a defense or adaptation action.

\section{Coping: Psychological Defenses and Adaptation}

Resilience involves an analysis of protective factors (which include defense capabilities) that would allow an estimate of the theoretical ability of the individual to adapt to and withstand psychological trauma. According to Szerman (2006, p.23), the right protective factors are those 'that reduce the impact of risk, reduce the likelihood of chain reactions, build self-esteem and a sense of self-competence, and lead to positive opportunities.'

These factors can be divided into three categories: factors related to the individual and his personal resources, factors related to the family environment and those related to the extra-familial social environment (including the company) (Mills et al., 2020; Weaver, 2008).

\section{Individual Factors}

Individual resilience factors are linked to good intellectual functioning (particularly to deal with trauma by having the ability to trigger a psychological coping strategy to solve problems), relational skills such as empathy, self-confidence that often induces self-esteem, a positive vision from a strong belief system and a good use of psychological defense mechanisms: denial, cleavage, sublimation, intellectualization and avoidance, minimization...). Positive emotions using humor, relaxation techniques and optimistic thinking are also an important element of resilience (Taylor et al. 2019; Tugade \& Fredrickson, 2004).

\section{Family Factors}

The family environment can represent a significant obstacle for the future resilience of the individual when he suffers from parental imbalance like chronic misunderstanding or violence, serious illness, alcoholism, single parent structure, father or mother often absent, divorce, death ... (Szerman, 2006). On the contrary, a comfortable and secure family environment will foster resilience. Examples include good education, warm relationships with both parents, feelings of family warmth, parental emotional sensitivity and perceived security attachment (Cyrulnik, 2002).

\section{Socio-Environmental Factors}

The psychologically fragile being who suffers trauma and cannot withstand it alone will tend to increase the risk factors to the point where he can never do it again; it is the vicious circle. This is why someone, a confidant must one day be able to be "accidentally" met to break this vicious circle (Stein et al., 2000; Taylor et al., 2019). He is the resilience tutor. He can be a friend, a doctor, a teacher, a simple neighbor, a manager, a coach... (Afifi, 2018; Weaver, 2008). He is also called: the care giver or care taker among Anglo-Saxons, the mentor in Canada (Szerman, 2006). The resilience guardian replaces the deficient parent to restore the desire of the traumatized to rebuild a life project that makes sense to him and thus restores him self-esteem and self-love.

These latter factors allow us to build the link with the type of resilience that interests us, namely that of the individual within the socio-cultural context of the company whose organization has just suffered a serious crisis. Such crisis is likely to affect everyone in a traumatic way and thus potentially trigger the process of resilience in individuals.

In short, these defense mechanisms appear to be essential in order to allow psychological adjustment (coping) and then once the balance protection/adaptation has been achieved: resilience. However, the second trauma, self-perception or social sanction, must find answers beyond these defense mechanisms. Resilience goes beyond that, it must allow reconstruction, which is often referred to in common parling: bounce.

\section{Reconstruction}

Reconstruction transforms the negative representation of trauma into a positive vision. The real wound will always exist, even after adjustment (coping), but its positively transformed representation will make it much more bearable. This reconstruction work could take a long time. First, it will have to go through understanding and action to restore meaning to an existence that has not had any since the trauma (Cyrulnik, 2004; Hines et al., 2021). Understanding comes from the environment that should play the role of the resilience guardian leading the resilient to find a 
second strength that will allow him to temporarily close his scars of the past, open the way to a new life and make him a new meaning capable of ensuring his survival (Cyrulnik, 2002).

'Let us see how meaning can manifest itself through action. Experience shows that resilience often requires a project to be implemented, a goal to be achieved' (Vanistendael \& Lecomte, 2009, p.19). Post-traumatic action, which must accompany the acceptance of the injury by the individual, can find answers through great projects and challenges that will help him to regain and restore meaning to life (Vanistendael \& Lecomte, 2009).

\section{Post-Resilience Learning}

The second question about post-resilience is: Is resilience learned over time? This question is important: ' $R \boldsymbol{e}$ searchers need to consider the possibility of learning to be more resilient.' (Bonanno, 2004, p.3).

Resilience learning depends on a synchronized encounter between the arrangements/capabilities of the individual's moment and the opportunities provided by the family or social environment. However, it remains possible to learn from the experience of the resilient to better understand and approach both individual and environmental factors or characteristics that allow the resilience process to first trigger and then allow the healing of the traumatized (Taylor et al., 2019). In the absence of the individual's ability to learn from resilience, we suggest that the family or the environment can learn from resilience to understand that it can facilitate its triggering in the individual who needs it.

\section{Individual Resilience in the Organization}

The resilience of the individual does not necessarily match the direction expected by the organization when it is hit by the crisis. The individual may indeed prefer his own survival to that of the company and, first of all, protect himself with his own defense mechanisms. Then, the organization must work upstream to prevent this trend by developing a climate and collective cohesion sufficient to be able on D-Day to allow the collective to exceed personal protections to preserve its longevity. 'If resilient individuals all interpret reality differently, their decisions and actions will be in conflict, risking the survival of the company in times of crisis' (Coutu, 2002, p.32).

Note that a crisis is defined according to Roux-Dufort (2003, p.6) as 'a process that, under the effect of a triggering event, awakens a series of dysfunctions.... Crisis is a process that alternates the long incubation and gestational phases in the company, and short and acute phases of destructive and brutal manifestations.'

The responses of the organization to individual resilience in the face of crisis are linked to three theoretical areas: structuring, emotion and leadership.

From a structuring perspective (Giddens, 1979), we consider that the structural ownership of an organization is materialized by the conditions and results of actions produced by its agents. Then, it is not possible to separate structure and action as they are interconnected. Moreover, the structure makes it possible to develop skills, exchanges of routines and common values allow individuals to become actors (Branicki et al., 2019; Giddens, 1979; Yates \& Orlikowski, 1992). However, this same structure can lead to limits in human action at the same time. Therefore, any organizational result is both made possible but also limited by structure.

We postulate that resilience as a result is no exception.

A study on resilience also requires a strong recognition of the role played by emotion in organizations. Indeed, the activation of organizational behaviors is conditioned by emotion (Damasio, 1994; Diener et al. 2020). Emotion is a contagious phenomenon that is conveyed through a group and presents an indispensable force in the activation of an organized collective process (Gump and Kuclick, 1997). On the other hand, negative emotions limit the ability of individuals to implement positive collective action. On the contrary, individuals are in favor of positive collective action when their emotional system is stable and positive (Diener et al., 2020; Nguyen Huy, 2002).

Then, emotion is seen as a factor in resilience.

The third useful theory is leadership. As Weick et al. (1999) and Schein (2004) point out, the meaning of action depends on the influence of the leader on the representation of his subordinates. For example, Schein (2004) insists that the leader is a creator of organizational culture that will become the 'cornerstone' of employees' behavior. In general, research trends dealing with the importance of professional relations between managers and collaborators postulate that a degraded relationship with the manager will lead to suffering for the employee, while a good relationship will promote the development and enrichment of the skills essential to resilience (Bhaduri, 2019; Reis \& Gable, 2003).

Therefore, we postulate that leadership is one of the resources that can provide a context conducive to individual resilience. 


\section{Research Methodology}

Our research objective is to explore managerial practices that promote individual resilience in the organization. Given the limited number of work on this topic, a qualitative study seemed to be an appropriate solution (Wacheux, 1996).

We used in-depth semi-structured interviews as the primary means of data collection. It is a research method that 'allows the researcher to extract very rich and nuanced information and reflections' (Quivy and Van Campenhoudt, 1995, p. 194).

In order to limit elite bias (Miles \& Huberman, 2003), we conducted interviews with all levels of management, executives and non-executive employees. The aim was to allow as much as possible exploration of employee perceptions (Yin, 2003). Sixteen interviews were conducted over a period of more than six months from March to August 2020 with an average duration of $45 \mathrm{~min}$ with each interviewee. We have divided our interview guide into four main themes: (1) the presentation of the company and the profile of the interviewee; (2) the repercussions of the crisis on the company and its influences on the trauma of the actors; (3) individual resilience processes and the role of the organization in these processes; and (4) lessons learned from the experience of individual resilience in the company.

The method used for data processing is the analysis of thematic content (Miles \& Huberman, 2003). We have developed a list of codes: they are 'labels' that contribute to data processing. The progress of our analysis was marked with the shift from descriptive coding to more explanatory coding.

While descriptive coding involves synthesizing segments of data, explanatory coding aims to group these summaries into fewer themes or more synthetic conceptual elements' (Miles \& Huberman, 2003, p. 133). The use of qualitative data processing software-Nvivo 12 softwarefacilitated the structuring of the analysis work. The objective of this tool is to extract concepts from a corpus, to develop a network of relationships between these concepts and to identify the most common nuclei of meaning and their characteristics in order to achieve final results (Andreani \& Conchon, 2005).

We selected sixteen large- and medium-sized Tunisian companies from various sectors. We believe that our sample (20 cases) corresponds to the principle of theoretical case saturation recommended by Yin (2003). Those companies experienced great difficulties as a result of the negative repercussions of the 'COVID-19' crisis but were able to withstand and survive especially after the total containment imposed by the Tunisian State during the months of March and April 2020.

We detail in the table the characteristics of our study sample (Table 1).

\section{Results}

The COVID-19 pandemic is not exclusively a health crisis. It is also an economic crisis that has generated a large-scale psychosocial impact on businesses, particularly employees. This crisis is at the source of several psychosocial risks that vary according to the involved parties: fear of closing their companies following a possible bankruptcy for the executives. Anguish of losing their social and hierarchical positions for senior managers. Anxiety and burnout for those are still at the workstation. Stress on the date of return to work or even of non-return and the emotional deficit related to the lack of co-worker and professional warmth for those confined. Lack of motivation on a daily basis for teleworkers that leads to disruptions in the pace of work due to the urgent action... Thus, like their counterparts around the world, Tunisian companies are urgently working to protect the health of their employees and build their resilience to cope with the crisis.

"Regardless of the negative effects of this health crisis, our organizations must seize the opportunity to challenge ourselves on an individual, collective and organizational level. In this time of crisis, it is time to give priority to 'Man', his health, his safety and his well-being. The time has come to reinvent a social contract capable of instilling confidence and creating a workforce with a dynamic resilience capacity" (I9).

Through our empirical study, we aim to explore in a real organizational context the functioning of individual resilience processes through its four phases: trauma phase, psychological adaptation phase, reconstruction phase and post-resilience learning phase. We will analyze these four phases in detail in the following sections.

\section{Trauma Phase}

Following the advent of the COVID-19, the life of any business was turbulent. Totally blocked, the company is unable to respond in times of anxiety, uncertainty, depression and tension paralyzing its activity. The world of work is changing, affecting everyone, regardless of his place in the organizational hierarchy and his professional, family and social life.

"The fallout from the crisis is traumatic, and the procedures put in place are restrictive and put a lot 
Table 1 Sample characteristics

\begin{tabular}{|c|c|c|c|c|c|}
\hline Case & Activity & Work force & Interviewees & & Duration of the interview (min) \\
\hline $\mathrm{C} 1$ & Food & 3300 & General manager & I1 & 45 \\
\hline $\mathrm{C} 2$ & Insurance & 3000 & Exploitation manager & I 2 & 40 \\
\hline C3 & Bank & 2700 & Exploitation manager & $\mathrm{I} 3$ & 48 \\
\hline $\mathrm{C} 4$ & Chemic industries & 2300 & Employee & I4 & 46 \\
\hline $\mathrm{C} 5$ & Pharmaceutical & 2000 & Hygiene and environmental manager & I5 & 45 \\
\hline C6 & Metallic industries & 1700 & CSR manager & I6 & 60 \\
\hline $\mathrm{C} 7$ & Metallurgical industries & 1500 & Manager of quality, safety and environment & I7 & 50 \\
\hline $\mathrm{C} 8$ & Construction materials & 1100 & Laboratory technician & I8 & 45 \\
\hline C9 & Recycling and environment & 900 & Health and safety manager & I9 & 40 \\
\hline $\mathrm{C} 10$ & Electric industries & 880 & Manager of sustainable development & $\mathrm{I} 10$ & 55 \\
\hline $\mathrm{C} 11$ & Digital and IT & 800 & Deputy managing director & I11 & 35 \\
\hline $\mathrm{C} 12$ & Real estate & 770 & Communication manager & $\mathrm{I} 12$ & 40 \\
\hline $\mathrm{C} 13$ & Tourism & 680 & Manager & I13 & 49 \\
\hline $\mathrm{C} 14$ & Ceramics and glass industries & 620 & Research and development manager & I14 & 41 \\
\hline $\mathrm{C} 15$ & Paramedical & 550 & Chairman and CEO & $\mathrm{I} 15$ & 60 \\
\hline $\mathrm{C} 16$ & Cosmetic & 460 & Social assistant & I16 & 50 \\
\hline
\end{tabular}

of pressure on everyone in the company. It is truly a traumatic process for those who manage and experience it. We are in a real battle inside, within ourselves, and on the outside, in the face of the new situation of the company, so it is necessary to find alternatives to all this" (I7).

Therefore, it is a traumatic situation that has created psychosocial risks in the following areas: safety, survival, continuity of work, containment, information.

We will analyze these axes in depth in the following part.

\section{Security}

The exponential spread of coronavirus perceived by employees during the pandemic period has created fears about their health and health of others. Such fears are heightened by the prospect of joining a group that can transmit the virus, and they are a source of psychosocial risk to be treated as such. On the one hand, the risk of high contamination has led employees to legitimately doubt the workspace as a place of survival and development. On the other hand, this risk is accentuated by situations of tension induced by the health situation: aggression between employees or outsiders (e.g. customers or suppliers), exaggerated suspicion, tearing of the social bond ...

"A microscopic enemy had just torn the fabric of our daily lives, leaving us stunned and full of worry. The anguish of being infected with the virus has led to the loss of trust in our colleagues, outsiders and workspaces" (I11).

\section{Survival}

The COVID-19 crisis reminds the collective memory of the fragility and vulnerability of human beings. In 2020, death has been mentioned all over the World and in all organizations. Its presence confronts us with a singular dimension of existential therapy: the finitude of life. This situation has taken away among all employees the multiplication and intensification of suffering: stress, insomnia, uncertainty, apathy, if not despair. In short, sad passions led them to waiting for the end of the tunnel.

"Since the beginning of the pandemic, and more and more over time, we have all seen either a colleague who has died of this virus or colleagues who have lost one of their own. Of course, for us humans, it generates anxiety: when will my turn come? The one of the people I love? Could I escape it?" (I8).

\section{Professional Continuity}

COVID-19 resulted in economic hardship threatening the survival of many organizations. This situation has pushed all the players: entrepreneurs, managers, operational agents (technicians) and workers to worry about the future, or even the sustainability of their companies and their jobs. This worry about the uncertainty of the future stimulated 
feelings of fear, insecurity, worthlessness and disunity among actors.

\footnotetext{
"The economic difficulties experienced by our company and the resulting restrictive redundancy measures are traumatic. Feelings of insecurity, worry and fragility about the future of all the players in the company, whatever their position, were the key words of the situation. Examples of worrying questions: can I ensure the continuity of my business (by entrepreneurs)? Will I be able to preserve my job or will I be laid off (workers and technicians)? If I lost my position, what would be my alternatives (by managers)?" (I4).
}

\section{Information}

During the spread of coronavirus, false information and rumors in companies intensify, especially in terms of the social and economic impact of the pandemic and organizational responses. Unfortunately, this information is harmful and develops anxieties with its alarmist approach and its massive spread. Backed by misinterpretations, they reinforce the mechanisms of psychosis and make it difficult to bear situations for which employees are unfortunately not sufficiently prepared.

\begin{abstract}
"Yes, infobesity and rumors in these times of crisis are anxiety-inducing and only push our fears about the unknown and they can develop forms of hypochondria as well as irrational attitudes (pullbacks, racism towards the infected, virus of whites...). But this rampant information pandemic has also allowed us to be aware of the negative impacts that information can have on our moral psychological health and to adopt distancing behaviors like those advocated for COVID-19" (I12).
\end{abstract}

\section{Confinement}

The government decree of 20/03/2020 imposed general national confinement in Tunisia. Deployed in haste, remote work has imposed itself in all companies, thus lifting the latest resistance of managers for telework. However, confinement, physical distancing and communication by digital online means (videoconferences, phone calls, emails...) make non-verbal communication difficult and reduce the perception of the other's emotions. The unprecedented situation in this rhythm has accentuated already wellknown risks: blurring the boundaries between work and personal life, isolation and psychosocial issues (work workload, work rhythm, difficulties in distancing themselves from work, addictions, family conflicts, etc.).
Prolonged isolation has caused some employees symptoms of stress, confusion, anger, fear, frustration, boredom, stigma... In short, post-traumatic symptoms can have an impact on life at work.

"In times of confinement, some of the employees have been affected by the breakdown of social contact, children at home, material or technological difficulties, promiscuity, isolation, professional dropout, sense of worthlessness... All of this had a differentiated impact on how they were able to live and work during this period" (I2).

\section{Psychological Adjustment Phase}

In this exceptional pandemic situation linked to the COVID-19, the operation of companies was affected to different degrees during the confinement: closures, activity limitations, reorganizations... Employees were also affected by post-traumatic stress disorder that generates negative emotions: stress, worthlessness, despair, depression... The gradual resumption of activity toward a stabilized situation raises many questions and requires preparation to facilitate conditions of success, both for the continuity of the company's activities and for the preservation of employees' health and safety. At this level, an exercise in psychological adaptation of all individuals in the company is necessary to trigger their resilience. 'The goal of this phase is to give the feeling that everything was positive and under control' (I5).

Our empirical study highlighted four factors that support the development of this adaptation phase: proximity coaching, involvement of social partners in decision-making, HR Business Partner and leadership. We detail these four factors in the following part.

\section{Proximity Coaching (PC)}

In some companies, 'Proximity Coaching' is an essential $\operatorname{cog}$ in the implementation of adaptation of the working arrangements for the resumption of activity. It encompasses all the structures involved in the management of the health crisis such as: staff representatives, security and hygiene services, crisis cell, HR, occupational health service... Its role is decisive, on the one hand, in the transmission of the information provided by the company to its employees on the means it implements to limit the risks of transmission of the disease within the company. Doing so, it answers questions and mitigates these fears. On the other hand, in the uplift of information from employees and in the identification of situations of psychological fragility due to the context. 
In addition, $\mathrm{PC}$ takes care of making an individualized welcome of the employee deconfined through active listening and inquiries about individual situation. This time of welcome made it possible to formalize the return and identify complicated individual situations to eventually propose personalized care by the occupational health service, the human resources department and the social worker of the company...

PC also arranges and plans specific training, on the one hand, on the risks associated with COVID-19, and on the other hand, on the health and safety measures taken by the company to fight against the coronavirus pandemic.

In short, the assistance of the employees by the close supervision helped to assuage their feelings of concern and anxiety about their safety and physical serenity.

\begin{abstract}
"Already guarantors of cohesion during the containment period, local managers will be on the front line to facilitate the gradual return of employees to a more traditional way of working. They will have to deal with employees with heterogeneous statuses and a team in a fluctuating format. The purpose of PC is to assuage employees' feelings of concern and anxiety about their physical safety. Giving the impression that everything was controllable and spreading positive waves and emotions is its first mission" (I3).
\end{abstract}

\section{Involvement of Social Partners in Decision Making}

Some companies have prioritized an approach of openness and social dialog with social partners and internal stakeholders to find and accept the potential solutions. At such time of crisis, social partners are seen more as interlocutors who make things happen than as a threat or source of conflict. The Personnel Representative Bodies (PRDs) were involved in the concept and the design and implementation of deconfinement modalities because these modalities will have a significant impact not only on health and safety, but also on the prevention of conflict and psychosocial risks. PRDs have been involved in the development of various crisis management plans such as a backup plan, a continuity plan and a business recovery plan. These plans have been designed with a concerted and iterative approach to better anticipate the impact on future work and ad hoc prevention measures. In the end, this involvement of PRDs has helped to reduce the feeling of insecurity of employees.

\footnotetext{
"PRD's involvement in social dialogue and decisionmaking reflects our participatory approach to managing this health crisis. This has reduced employees' sense of insecurity by making them feel that they are involved in decision-making in the
}

company and that they are involved in the implementation of anti-crisis solutions" (I6).

\section{HR Business Partner}

The HR function, halfway between support and technostructure, has emerged as an effective party for the implementation of measures initiated by the government and the company. The Human Resources Directorate (HRD) is strengthened, affirming its role as HR Business Partner of management and internal advice to managers (on telework). Suddenly, HRD's priorities at the time of the health crisis have changed. During the crisis, HRD is called upon to mitigate the economic and social impact of the pandemic by avoiding — or at least reducing — collective redundancies and loss of benefits through the implementation of an Employment Safeguarding Plan (ESP), to conduct effective internal communication to ensure the success of hygiene and safety measures and to organize the resumption of activities after confinement.

The ESP is a regulatory scheme that aims to avoid mass layoffs or limit the number of redundancies, thus creating a sense of psychological security among employees. The ESP has enabled employees to guarantee their financial and moral rights in the event of dismissal and preserved the maximum number of skilled workers. Among the measures taken under ESP: internal transfer or reclassification; retention in employment in return for reduced working hours or reduction in pay; conventional breakage; Partial Unemployment; Autonomous departure; Supporting business start-ups, Help with training or conversion state compensation for vulnerable employees....

"The ESP is a double-edged sword. On the one hand, it has allowed us to preserve the maximum of our workforce through temporary cost optimization measures such as hourly adjustments or even partial unemployment. On the other hand, it offered employees a sense of calm and psychological security about their future, whether in terms of employment or financial and moral rights" (I10).

The return to the company after the containment did not happen without questions about the sustainability of the company, the evolution of the situation and the security measures...

At this level, HR has ensured that hygiene measures (hand washing, hydro-alcoholic soap and masks, social distance, etc.) are available on a regular basis and in a transparent manner; occupational health and safety conditions (less confined office, reorganization of services to reduce contacts; tactile holograms, protocol for the care of infected employees...); reconfiguration of management 
(telework, digitalization, mobility, change of procedures...). Also communicate even when there is no new information, to avoid rumors, misinterpretation and fear.

\begin{abstract}
"Communicating continuously and transparently about the current situation and the future of the company is a good way to mitigate the mechanism of psychosis and promote psychological defense mechanisms to absorb the negative emotions of anxiety, uncertainty, apathy, stress...” (I15).
\end{abstract}

\section{Leadership}

The health crisis has disrupted the usually directive managerial practices. Faced with this paradigm shift, managers had to adapt and rethink their ways of managing teams. They were pressured to master the main codes and peculiarities of change while preventing and limiting the potential intense psychosocial risks (isolation, stress...).

Since then, the practice of corporate leadership has evolved toward a focus on three practices:-communicating: staying confined does not mean being isolated, hence the need for open communication to free employees' speech, encourage and keep them informed of developments and develop action plans together taking into account their feedback; - flexibility: away from the office but not far from work. The most effective leaders know how crucial flexibility is, especially during the crisis and focus on essential tasks with adjustable timelines. To endure the time of the storm, the less significant tasks are time and energy saving;- - accountability: requires building trust between employees and with the hierarchy, listening, supporting and benevolence to employees facing fear of disease and the prospect of losing their jobs in a degraded economic environment.

"However, leadership practices have evolved in times of crisis. We have new technological tools to strengthen the connection with our teams, we have learned to be more personal, more empathetic while respecting the privacy of each. For the employees, the values of the leader and his ability to take care of the team and embody a response to the crisis have become essential to foster their resilience and face adversity" (I14).

\section{Reconstruction Phase}

After a period of adaptation to a series of traumas, the organization should systematically generate a need for usefulness and meaning to action. This is going to be a real issue of loyalty, motivation and therefore success and performance favoring the reconstruction of a positive image of the organization in the eyes of its employees. This phase consists in leading a change within the organization adapted to this new paradigm of crisis and perceptible by employees.

"After preparing our employees to adapt to the traumas of the crisis, we have implemented structural changes in which individuals, regardless of their positions in the company, are the real actors. From there, we tried to build the values that underpin the 'common' with all the employees. The goal is to rebuild the company's image in the eyes of employees and assign them new roles as pillars of change. Concepts such as Reactivity, Creativity, Flexibility, Proximity, Dialogue, Responsibility and Ethics are characteristic dimensions of our managerial practices" (I13).

At this level, the agility which organizations have had to demonstrate attests to strong repercussions in terms of management. Specifically, three categories of impacts are identified and contribute to the transformation of work.

(1) The impact on the organization of work. The use of telework has changed work in its place and in its spaces, but also in its organizational methods by using new tools (mainly digital) announcing the evolution toward a more agile organization in a V.U.C.A. world (volatility, uncertainty, complexity, ambiguity).

(2) The impact on managerial practices. Structures have moved from Top-Down Management to increasingly horizontal and cross-cutting, more decentralized, agile and flexible management, giving way to autonomy and initiative, which paved the way for ingenuity, resourcefulness, initiative, creativity, adaptability and responsiveness to maintain business continuity. As a result, managers have given up the practice of "command and control" to evolve into management based on conviction, adherence, autonomy at work and professional support.

(3) The impact on the physical and moral well-being of employees. Health policy has risen to the front to fight against a terrifying virus. More than ever, companies have a crucial role to play in protecting people's health, including the implementation of hygiene measures in all workplaces and the use of remote work (a strong component of life reconciliation) to protect the health and physical well-being of workers.

"The employees will come out of the experience that I qualified as "confined work" with new expectations with regard to work, management and health. We reacted positively to these expectations.First, 
becoming mixed, the work is adapted to distance as well as face-to-face. Second, unable to adopt "command and control" yet, management has evolved into a practice based on membership, responsibility, autonomy, cooperation and professional support. Third, the well-being of employees becomes a strategic concern" (I16).

\section{Post-Resilience Learning Phase}

During the health crisis, new practices and organizational methods were inevitably adopted in companies to promote the resilience of individuals and thus ensure their role in the resistance to the health crisis. However, the pandemic is not yet over, so the risks of resurgence of the COVID-19 virus through a second or even a third wave or other pandemics are still plausible.

Therefore, a feedback is important to take stock of this period and not to leave as if nothing had happened. After a first look back at how everyone's time was lived, it is a matter of learning from how the company and the workforce have functioned to value and preserve what has been virtuous and highlight the difficulties experienced by employees. This progress point was made at different levels of the company, collectively and in a participatory way, with employees and their management, human resources departments, with staff representatives and occupational health actors of the company. The impetus of the management of the company is necessary in this phase.

According to our interviews, the points that have been mentioned in the feedback are:

- Recognize the efforts made during the crisis, value the development of skills that may have taken place like autonomy, versatility, inventiveness, commitment shown by employees in this particular situation.

- Support and cultivate the sense of usefulness that employees may have felt in their activity, whether they were confined or in the company. The health crisis has highlighted what is usually considered in some cases to be easy, natural and with little or no qualifications or skills.

- To provide a participatory opportunity within the teams to formalize and establish new ways of doing things, the new functional links that have developed during the crisis and which have proven to be effective and secure. New terms of exchange based on trust and reciprocity will have been practiced and will be retained.

- To preserve and develop new forms of work organization that have proven to be more fluid, more flexible...

- Identifying what did not work and what was very expensive for employees in terms of psychological load. To this end, it is possible to take stock of the situation in relation to the main psychosocial risk factors.

"The prevention of new waves of COVID-19 pandemic will necessarily has led our company to evaluate the new arrangements that have been put in place to promote the resilience of our employees and which are both strategic (policy and long-term objectives...) organizational structure, tools, procedures, work organization, etc.). The aim is to ensure that we are vigilant and act appropriately in the event of further disruptions" (II).

\section{Conclusion}

Organizations have to deal with an increasingly complex and unstable environment of which the COVID-19 crisis is a symptom in order to develop. The crisis will leave traces both at the corporate and individual levels.

Behind this categorization is a polymorphic reality: anxious entrepreneurs about the eventual closure of their businesses and worried workers at the workplace. There are also the teleworkers who are behind the scenes and supporters of the activity and confined teams who are without means of work or held in custody of children. Besides, there are managers who are suspicious of the continuity of their social and hierarchical positions within the companies that employ them.

However, history shows that 'Man' has always been able to overcome the throes of crises thanks to collective intelligence, adaptation and above all resilience. However, the individual can partially improve his/her protective factors and limit his/her risk factors. In the absence of the individual's ability to learn from resilience, the organization can learn from resilience to support them in the event of trauma. In this sense, we have shown that the company must strengthen the psychological protective factors of its employees, which will promote their individual resilience in the organization. In this research, we have tried to identify organizational responses to the individual resilience process in the context of the COVID-19 health crisis.

We studied these responses and processes in twenty large- and medium-sized companies that were affected by an accumulation of incidents caused by the COVID-19 epidemic but were still able to survive. The observations were made possible by analyzing the content of interviews gathered with leaders/managers/workers who lived amid these crises. Then, the contribution of our research is to demonstrate that individual psychological resilience is a dynamic process that may or may not be triggered by a serious trauma, and that in a context of crisis, the company 
must provide a set of managerial practices allowing the psychological and above all social reconstruction of the individual thanks to:

- Triggering strategies for psychological adjustment of the individual. This requires a social dialog to involve all the structures involved in crisis management such as: the general management, supervisors, proximity, PRDs, HRD and managers in order to promote the defense mechanisms of the individual and allow him first to recover from the trauma and then to heal his open wounds;

- The prospects of evolution offered by the company to rebuild itself by giving back meaning to action through its involvement in creative projects of change that transforms the experienced trauma into a source of satisfaction and motivation;

- Post-resilience learning allowing it to develop protective factors derived from its own abilities but also from the abilities accumulated over time thanks to the sociocultural environment and especially the company to deal with future traumas.

In the end, it should be noted that the originality of our research is based on the fact that it was inspired by work on individual resilience emanating, on the one hand, from psychology in relation to trauma particularly (Chen \& Bonanno, 2020; Cyrulnik \& Morin, 2010), adaptation 'coping' (Brissiaud, 2008; Mills et al., 2020) and psychological defense mechanisms (Afifi, 2018; Szerman, 2006). On the other hand, organizational science and in particular the work carried out within the framework of the structure (Branicki et al., 2019; Poirot, 2007), emotions (Diener et al. 2020; Nguyen Huy, 2002) and leadership (Bhaduri, 2019; Schein, 2004). However, our results are reflected in management practices and more particularly, on the one hand, in a very specific crisis paradigm that of COVID-19, on the other hand, in a Tunisian context.

Therefore, we believe that our research brings managerial implications, particularly in terms of the role of HRM in crisis management. Indeed, the HR function has undergone a series of reorganizations and changes making it a true partner of management in times of health crisis. These changes are reflected in job reconfigurations that will have to be accompanied by consideration of workers' rights; implementation and monitoring of the rescheduling of HR budgets (panoptic frugality); the adoption of Peretti's 'Contingent HRM Model' (2020) focused on the PAMPA (Personalization, Agility, Mobilization, Sharing and Anticipation) logic applied to the administrative strategy of organizing and managing emergency, crisis and risk; recruiting resilient people who are flexible, adaptable, creative and confident and whose behaviors in uncertain situations will be driven more by opportunities than by dangers.

However, despite its contributions, these results presented should not be considered beyond their exploratory nature and whose scope is to provide a first presentation of the concept of individual resilience in an organizational context. They are indeed imbued with a strong subjectivity. On the one hand, the interviewees had their own interpretation of the events that are directly experienced by them during the crisis. Nevertheless, the latter have certainly unconsciously brought different filters to the reality as reported (selection of certain facts and not others, sorting, evaluation of their importance....). On the other hand, the researcher in his coding was also subject to the influence of his own interpretations of the interviews carried out and therefore certainly influenced the proposed results.

The other restriction that we wanted to point out is the non-existence of representativeness of the counter-group, that is to say the companies that have disappeared following the health crisis, and therefore have not succeeded in preparing their individuals for the resilience exercise.

However, we recommend limiting the subjectivity of the results of this article in future research by, on the one hand, increasing the number and variety of interviewees on the same case (different populations such as managers, employees, stakeholders, etc.). On the other hand, by carrying out coding of the same case by several researchers. Finally, it would also be interesting to continue our initial findings, but this time in companies that have not been able to demonstrate sufficient efficiency in resilience processes to survive the crisis; companies that have already perished. This path of research will help identify the factors that caused the dysfunction of individual resilience processes in a real organizational context in times of health crisis.

\section{Declaration}

Funding No funding.

Conflict of interest The authors declare that they have no known competing financial interests or personal relationships that could have appeared to influence the work reported in this paper.

\section{References}

Afifi, T. (2018). Individual/relational resilience. Journal of Applied Communication Research, 46(1), 5-9.

Ahmed, S., Taqi, H. M. M., Farabi, Y. I., Sarker, M., Ali, S. M., \& Sankaranarayanan, B. (2021). Evaluation of Flexible Strategies to Manage the COVID-19 Pandemic in the Education Sector. Global Journal of Flexible Systems Management, https://doi. org/10.1007/s40171-021-00267-9.

Altintas, G., \& Royer, I. (2009). Strengthening resilience through post-crisis learning: A longitudinal study of two periods of turbulence.M@n@gement, 12(4),266-293. 
Andreani, J. C., \& Conchon, F. (2005). Reliability and validity of qualitative surveys: A state of the art in marketing. French Marketing Review, 20(1), 5-21.

Bhaduri, R. M. (2019). Leveraging culture and leadership in crisis management. European Journal of Training and Development, 43(5/6), 554-569.

Blyth, M., \& Mallett, S. (2020). Epidemics and pandemics: Effects on societal and organizational resilience. Journal of Business Continuity-Emergency Planning, 14(1), 17-36.

Bonanno, A. (2004). Loss, trauma, and human resilience: How we underestimated the human capacity to strive after extremely aversive events. American Psychologist, 59(1), 20-28. https:// doi.org/10.1037/0003-066X.59.1.20

Branicki, L., Steyer, V., \& Sullivan-Taylor, B. (2019). Why resilience managers aren't resilient, and what human resource management can do about it. The International Journal of Human Resource Management, 30(8), 1261-1286.

Brissiaud, P. Y. (2008). The hidden side of resilience. Jouvence.

Chen, S., \& Bonanno, G. A. (2020). Psychological adjustment during the global outbreak of COVID-19: A resilience perspective. Psychological Trauma: Theory, Research, Practice, and Policy, 12(S1), S51-S54. https://doi.org/10.1037/tra0000685

Coutu, D. (2002). How resilience works. Harvard Business Review, $80(5), 46-55$.

Cyrulnik, B. (2002). A wonderful misfortune. Editions Odile Jacob.

Cyrulnik, B. (2003). The whisper of ghosts. Odile Jacob.

Cyrulnik, B. (2004). The naughty ducklings. Odile Jacob.

Cyrulnik, B., \& Elkaîm, M. (2009). Between resilience and resonance. Faber.

Cyrulnik, B., \& Morin, E. (2010). Dialogue on human nature. Paris, L'aube.

Damasio, A.R. (1994). Descartes error: Emotion, reason and the human brain. New York, Avon, (pp. 350-412).

Diener, E., Thapa, S., \& Tay, L. (2020). Positive emotions at work. Annual Review of Organizational Psychology and Organizational Behavior, 7, 451-477. https://doi.org/10.1146/annurevorgpsych-012119-044908

Elias, A. A. (2021). Kerala's innovations and flexibility for Covid-19 recovery: Storytelling using systems thinking. Global Journal of Flexible Systems Management. 22(Suppl 1), S33-S43.

Frimousse, S., \& Peretti, J. M. (2020). The lasting impact of the crisis on management. Management Questions, 2(28), 159-243.

Evans, S., \& Bahrami, H. (2020). Super-flexibility in practice: Insights from a crisis. Global Journal of Flexible Systems Management, 21(3), 207-214.

Gajdzik, B., \& Wolniak, R. (2021). Influence of the COVID-19 crisis on steel production in poland compared to the financial crisis of 2009 and to boom periods in the market. Resources. https://doi. org/10.3390/resources 10010004

Genet, J. J., \& Siemer, M. (2011). Flexible control in processing affective and non-affective material predicts individual differences in trait resilience. Cognition and Emotion, 25(2), 380-388.

Giddens, A. (1979). Central problems in social theory. London: Macmillan.

Gump, B. B., \& Kulick, J. A. (1997). Stress, affiliation, and emotional contagion. Journal of Personality and Social Psychology, 72(2), 305-319.

Hines, S. E., Chin, K. H., Glick, D. R., \& Wickwire, E. M. (2021). Trends in moral injury, distress, and resilience factors among health care workers at the beginning of the COVID-19 pandemic. International Journal of Environmental Research and Public Health. https://doi.org/10.3390/ijerph18020488

Michaud, P. A. (1999). Resilience: A new look at medical care and prevention. Pediatric Archives, 6(8), 827-831. https://doi.org/10. $1016 / \mathrm{s} 0929-693 \times(00) 88474-2$
Miles, M. B., \& Huberman, M. A. (2003). Analysis of qualitative data (2nd ed.). . De Boeck.

Mills, J., Ramachenderan, J., Chapman, M., Greenland, R., \& Agar, M. (2020). Prioritising workforce wellbeing and resilience: What COVID-19 is reminding us about self-care and staff support. Palliative Medicine., 34(9), 1137-1139. https://doi.org/10.1177/ 0269216320947966

Nguyen Huy, Q. (2002). Emotional balancing of organizational continuity and radical change: The contribution of middle managers. Administrative Science Quarterly, 47(1), 31-69.

Paramita, W., Rostiani, R., Winahjoe, S., Wibowo, A., Virgosita, R., \& Audita, H. (2021). Explaining the Voluntary Compliance to COVID-19 Measures: An Extrapolation on the Gender Perspective. Global Journal of Flexible Systems Management, 22(Suppl 1), S1-S18.

Paul, S. K., \& Chowdhury, P. (2020). Strategies for managing the impacts of disruptions during COVID-19: An example of toilet paper. Global Journal of Flexible Systems Management, 21(3), 283-293.

Peretti, J.M. (2020). Human resources management, Paris, Mr. Vuibert.

Poirot, M. (2007). The organization of individual resilience at work: First elements of analysis, CEREN Papers, (pp. 12-26).

Polas, M. R. H., \& Raju, V. (2021). Technology and entrepreneurial marketing decisions during COVID-19. Global Journal of Flexible Systems Management. 22(2), 95-112.

Quivy, R., van Campenhoudt, L. (1995). Social science research manual, Dunod.

Reis, H. T., \& Gable, S. L. (2003). Toward a positive psychology of relationships. In: Keyes, C. L.M., Haidt, J., (Eds.). Flourishing: Positive psychology and the life well-lived. American Psychological Association, (p. 129-159) https://doi.org/10.1037/10594006

Roux-Dufort, C. (2003). Manage and decide in a crisis. Dunod.

Schein, E. H. (2004). Organizational culture and leadership. JosseyBass.

Stein, H., Fonagy, P., Ferguson, K. S., \& Wisman, M. (2000). Lives through time: An ideographic approach to the study of resilience. Bulletin of the Meninger Clinic, 64(2), 281-305.

Szerman, S. (2006). Living and reliving, understanding resilience. Robert Laffond.

Tam, L. T., Ho, H. X., Nguyen, D. P., Elias, A., \& Le, A. N. H. (2021). Receptivity of governmental communication and its effectiveness during COVID-19 pandemic emergency in Vietnam: A qualitative study. Global Journal of Flexible Systems Management, 22(Suppl 1), S45-S64.

Taylor, C., Dollard, M. F., Clark, A., Dormann, C., Bakker, A. B. (2019). Psychosocial safety climate as a factor in organisational resilience: Implications for worker. Psychological Health, Resilience, and Engagement. Psychosocial Safety Climate, (pp. 199-228) https://doi.org/10.1007/978-3-030-20319-1_8

Tugade, M. M., \& Fredrickson, B. L. (2004). Resilient individuals use positive emotions to bounce back from negative emotional experiences. Journal of Personality and Social Psychology, 86(2), 320-333.

Ufua, D. E., Osabuohien, E., Ogbari, M. E., Falola, H. O., Okoh, E. E., \& Lakhani, A. (2021). Re-strategising government palliative support systems in tackling the challenges of COVID-19 lockdown in Lagos State, Nigeria. Global Journal of Flexible Systems Management, 22(Suppl 1), S19-S32.

Vanistendael, S., \& Lecomte, J. (2009). Happiness is always possible. Bayard Culture.

Wacheux, F. (1996). Qualitative methods and management research. Economica Edition.

Weaver, S. (2008). Resilience. University Press of France - PUF. 
Weick, K. E., Sutcliffe, K.M., \& Obstfeld, D. (1999). Organizing for high reliability: Processes of collective mindfulness, In: Sutton, R. I., Staw, B. M. (Eds.). Research in organizational behavior, Elsevier Science/JAI Press, vol 21, (pp.81-123).

Yates, J., \& Orlikowski, J. (1992). Genres of organizational communication: A structuring approach to studying communication and media. Academy of Management Review, 17(2), 299-326.

Yin, R. K. (2003). Case study research: design and methods (3rd ed.). . Sage.

Publisher's Note Springer Nature remains neutral with regard to jurisdictional claims in published maps and institutional affiliations.

\section{Key Questions Reflecting Applicability in RealLife}

(1) How can we measure the effectiveness of individual resilience in an organization?

(2) What is the link of influence between the processes of individual resilience and the processes of collective resilience in an organization?

(3) Does eco-environmental (which corresponds to processes obtained by external ecosystem regulation) resilience influence the resilience of the organization and consequently the individual resilience in the organization?

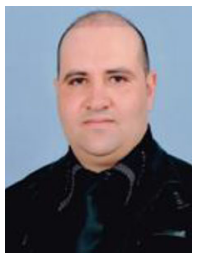

Bechir Mokline Bechir Mokline is research doctor at the Faculty of Economics and Management of Nabeul. He has five articles published, the details of which are follows:

- Mokline, B., and Ben Abdallah, M.A. (2021). "Organizational resilience as response to a crisis: case of COVID-19 crisis". Continuity \& Resilience Review, Vol. ahead-ofprint. https://doi.org/10.1108/CRR-03-20210008
- Mokline, B. (2021). "The Recognition of Business Opportunity in Female Entrepreneurship: State of Play in a Tunisian Context". Journal of Entrepreneurship and Innovation in Emerging Economies First Published Online April 24, 2021. https://doi.org/10.1177/23939575211010614

- Mokline, B. (2019). "L'impact du Lean Management sur la performance opérationnelle dans les entreprises tunisiennes". International Journal of Business \& Economic Strategy, 11 (1), 12-30. http://ipco-co.com/ IJBES/vol11/3.pdf

- Mokline, B. (2017). "Managing communicative conflicts and relational challenges in virtual teams". Human Systems Management, 36 (2), 115-127. https://doi.org/10.3233/HSM171755

- Mokline, B. (2014). "Confidence in Virtual Teams: Issues, interests and mechanisms for implementation". International Journal of Economics \& Strategic Management of Business Process, 2 (1), 141-152. http://www.ipcoco.com/ESMB/IEM'14\%20papers/285.pdf



Mohamed Anis Ben Abdallah Mohamed Anis Ben Abdallah is Assistant professor at the Faculty of Economics and Management of Nabeul. He has one article published, the details of which are follows:

- Mokline, B., and Ben Abdallah, M.A. (2021). "Organizational resilience as response to a crisis: case of COVID-19 crisis". Continuity \& Resilience Review, Vol. ahead-ofprint. https://doi.org/10.1108/CRR-03-20210008 